Nota Clínica

\title{
Tumores GIST con morfología quística
}

E. Marqués Medina, J. C. Palomo Sánchez, A. Cruz Cidoncha, M. J. Cantero Ayllón, P. J. Yunta Abarca, M. Á. Pérez Gil ${ }^{1}$, J. M. Saiz Jarabo

\section{Resumen}

La presentación poco común de los tumores estromales gastrointestinales como masa quística en los estudios de imagen abdominales hace que el diagnóstico preoperatorio no se sospeche. Algunas publicaciones sugieren que la variante multiquística en los GIST puede deberse al crecimiento de lesiones pedunculadas que provocaría congestión, edema y hemorragia. El diagnóstico de GIST debe tenerse presente ante una masa quística descrita mediante TAC o ecografía abdominal.

Palabras clave: GIST. Transformación quística. Tumores estromales.

Oncología, 2006; 29 (3):134-137

\section{Summary}

The unusual appearance of gastrointestinal stromal tumors as a cystic mass in abdomen imaging studies, often hides a correct or suspected preoperative diagnosis. A few reports suggest that the multicystic variance of GIST may occur as exophytic pedunculated specimens causing congestion, edema and hemorrhage during their growth. The diagnosis of GIST must be considered when a cystic mass is found in abdominal CT or ultrasonography.

Key words: GIST. Cystic changes. Stromal tumors.

Servico de Cirugía General y de Aparato Digestivo

${ }^{1}$ Servicio de Radiología

Hospital Virgen de la Luz

Cuenca

Recibido: 23.12 .05

Revisado: 12.01 .06

Aceptado: 24.01.06 


\section{Introducción}

Los GIST (gastrointestinal stromal tumors) son los tumores mesenquimales más frecuentes del tracto digestivo. Ha existido gran controversia con respecto a la nomenclatura, diagnóstico y pronóstico debida a la confusión histológica a la hora de clasificar la estirpe celular de estas lesiones. Actualmente representan una entidad bien reconocida como resultado de la aparición de un agente terapéutico específico y a la determinación por inmunohistoquímica del receptor KIT. El origen celular de estas neoplasias parece estar en la célula de Cajal, célula reguladora intestinal, ya que ambas estirpes expresan la proteína KIT y tienen características ultraestructurales similares.

Aunque macroscópicamente suelen corresponder a lesiones sólidas bien delimitadas, se describen variantes con componente quístico de crecimiento preferentemente exoluminal. En el último año se han intervenido en nuestro centro dos pacientes con tumoraciones gástricas de origen estromal con transformación multiquística.

\section{Caso 1}

Varón de 75 años que debuta con un cuadro de dolor abdominal e intolerancia digestiva. La TAC muestra una lesión de 14 x $7 \mathrm{~cm}$ de naturaleza quística de probable origen gástrico (Fig. 1). La laparotomía confirmó una lesión gástrica extramucosa con gran componente quístico multilocular (Figs. 2 y 3 ). Se realizó extirpación de la masa con resección local de espesor total de pared gástrica posterior y posterior cierre de la gastrotomía. El estudio histo-

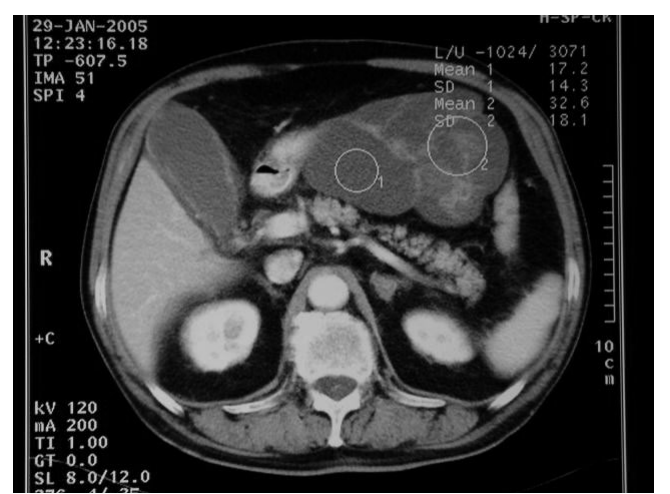

Figura 1. Caso 1. Imagen radiológica en la que se observa una tumoración multiquística dependiente de pared gástrica posterior.

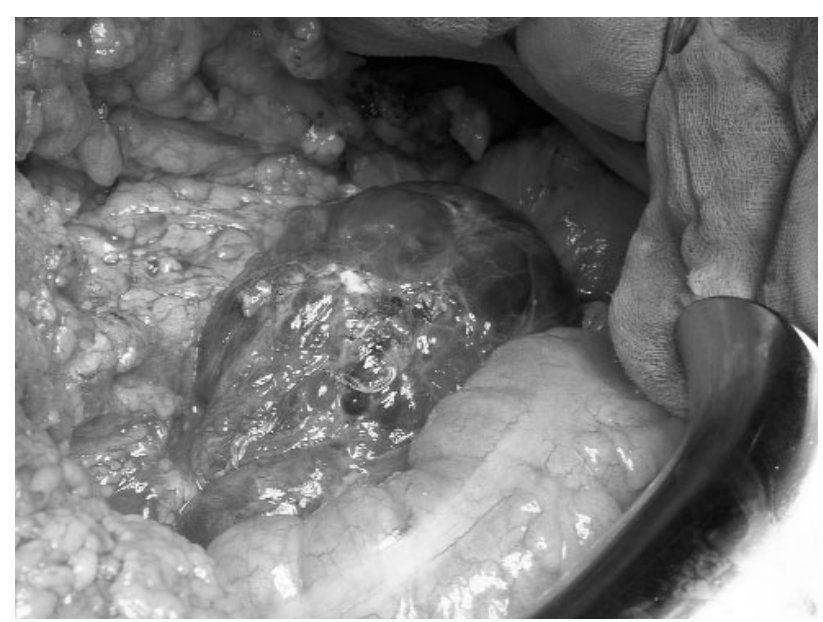

Figura 2. Caso 1. Campo quirúrgico en el que se aprecia la tumoración gástrica con gran componente exofítico

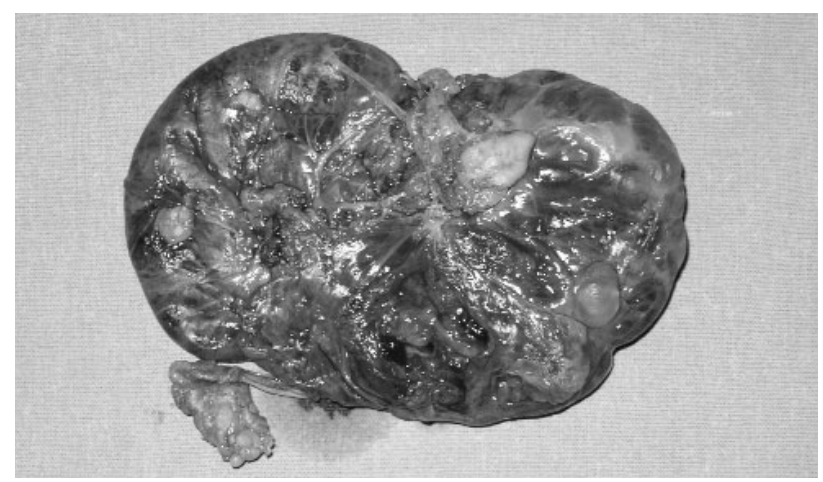

Figura 3. Caso 1. Pieza quirúrgica.

lógico describe una lesión de tipo estromal con transformación multiquística con expresión del gen KIT y CD34 con bajo potencial maligno (1mitosis/50 CGA).

\section{Caso 2}

Paciente varón de 37 años con clínica constitucional y de efecto masa en abdomen que en el estudio de imagen presenta una lesión multiquística de límites bien definidos de 20 x $20 \mathrm{~cm}$ dependiente de curvadura menor gástrica en íntimo contacto con lóbulo hepàtico izquierdo (Fig. 4). La intervención consiste en una exéresis tumoral con resección limitada de pared gástrica y resección hepática atípica del segmento III. El estudio de la pieza en este caso corresponde a un tumor de tipo GIST de origen gástrico con infiltración superficial del epiplon y adherencias inflamatorias a la cuña hepática. Presenta 


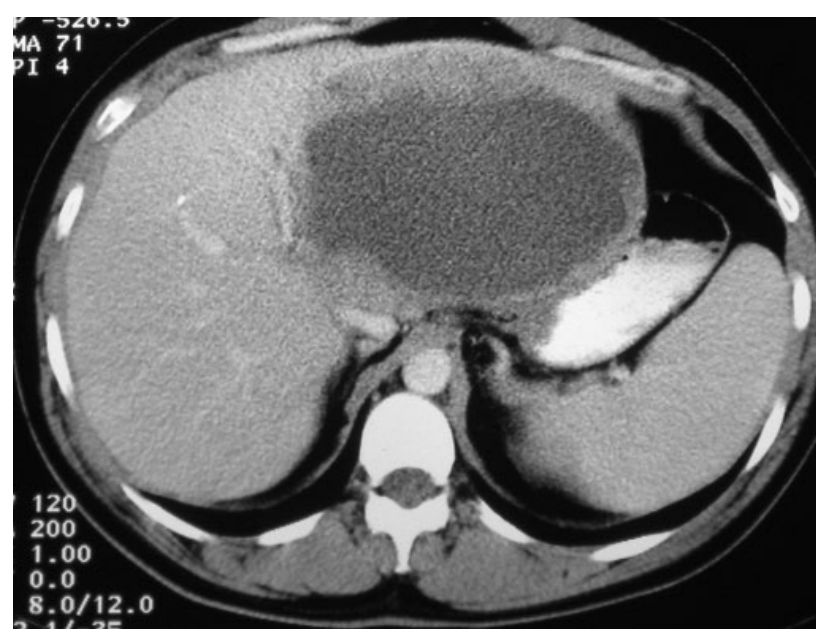

Figura 4. Caso 2. Imagen de la TAC en la que se aprecia una gran tumoración quística dependiente de curvadura menor gástrica en íntima relación con lóbulo hepático izquierdo.

extensa necrosis isquémica central con degeneración quística. El índice mitótico revela un alto potencial maligno (22 mitosis/10 CGA).

\section{Discusión}

Por su similitud con las células tumorales del músculo liso, estos tumores han sido incluidos como leiomiomas, leiomiosarcomas, leiomiomas epitelioides, leiomioblastomas o leiomiosarcomas epitelioides. Posteriormente se acuña el término de tumores estromales para reunir este grupo de lesiones histológicamente heterogéneo. El interés de reconocer estas lesiones desde el desarrollo de las pruebas inmunohistoquímicas reside en la aparición de una terapia molecular específica y efectiva.

Recientemente se ha propuesto que la mayoría de los tumores estromales derivan de las células madre mesenquimales que darían lugar a células de Cajal y a las células del músculo liso. Las células de Cajal se encuentran el el plexo mientérico del intestino entre las capas musculares circular y longitudinal y en el espesor de la capa de músculo liso. La función de estas células parece ser de regulación muscular, facilitan la propagación del estímulo eléctrico y median la neurotransmisión. Las células de los GIST y las células de Cajal presentan características estructurales similares y ambas expresan el receptor CD117. Ultraestructuralmente ambos tipos celulares presentan cierta heterogeneidad. Aunque la mayoría de los GIST muestran una apariencia estructural uniforme pueden distinguirse dos categorías histológicas principales. El tipo celular espiculado (70\%) y el tipo epitelioide $(30 \%)$. Aunque no hay relación directa entre el pronóstico y el subtipo histológico, el segundo parece presentar menor índice mitótico. Bajo visión de microscopio electrónico se observa mayor heterogeneidad. Algunas muestras pueden presentar microfilamentos de actina (propias de músculo liso), diferenciación neuronal y otros aparecen muy indiferenciados. La gran mayoría de los GIST demuestran inmunorreactividad para el receptor de la tirosin-quinasa KIT (antígeno CD117). La expresión del KIT se da en otras estirpes tumorales como en el melanoma, angiosarcoma, sarcoma de Ewing, mastocitoma y seminoma. El marcaje para CD34 está presente en el 70\% de los tumores, la tinción para actina de músculo liso en el $20 \%$, la proteína S100 en el 10\% y la desmina en menos del 5\%. Consensualmente se da el diagnóstico de GIST en los especímenes con morfología celular típica con marcaje positivo para el KIT.

La confusión en el diagnóstico al que hacíamos referencia hace difícil precisar la incidencia de los GIST. Se estima que en 2002 aparecieron $10700 \mathrm{ca}-$ sos nuevos en EEUU. En el momento del diagnóstico la mayoría de los pacientes se encuentran entre los 40 y 80 años afectando ligeramente más a los hombres. En raras ocasiones el tumor forma parte de una triada compuesta por GIST de localización gástrica, paraganglioma y condroma pulmonar denominada triada de Carney, que afecta a mujeres jóvenes. También se han relacionado con el síndrome de von Recklinghausen. Aunque suele ser esporádico se han descrito casos familiares.

En cuanto a la localización, los GIST aparecen en el estómago en dos tercios de los casos. La siguiente localización es el intestino delgado en el que representan el 25\% de los tumores. El 12\% restante se reparten entre el colon, recto y esófago. Iwashita y $\operatorname{cols}^{1}$. describen la morfología macroscópica en estómago sobre una serie de 81 casos con una incidencia de crecimiento endoluminal del $35,8 \%$, exoluminal del 33,3\%, intramural del $23,4 \%$ y un $7,4 \%$ de formas mixtas. Excepcionalmente pueden aparecer en epiplon, mesenterio, retroperitoneo e incluso vejiga.

La forma de presentación depende fundamentalmente del tamaño tumoral. Así como las lesiones 
menores de $2 \mathrm{~cm}$ se diagnostican incidentalmente durante una laparotomía o endoscopia, los de mayor tamaño provocan síntomas como dolor abdominal, masa palpable, síntomas compresivos, clínica obstructiva o sangrado por erosión de estructuras adyacentes. En el $25 \%$ de los pacientes se produce la necrosis e incluso la rotura espontánea del tumor independientemente de su tamaño.

La imagen tomográfica suele ser la de una masa sólida bien circunscrita adyacente a estómago o asas de intestino en ocasiones con componente hemorrágico o de necrosis. Algunos trabajos han intentado correlacionar las características radiológicas de la TAC con el grado de malignidad asociando el tamaño menor de $5 \mathrm{~cm}$, la ausencia de componente quístico y la buena definición de los límites de la lesión como predictores de benignidad ${ }^{2}$. La presentación quística es poco habitual lo que lleva a etiquetarlos preoperatoriamente como cistoadenomas, linfangiomas o mesoteliomas ${ }^{3}$. Esta variante no es dependiente del tamaño tumoral describiéndose transformación quística también en tumores pequeños ${ }^{4}$.

Debe tenerse presente la posibilidad de tumor es- tromal ante una lesión abdominal de aspecto quístico por las implicaciones terapéuticas. La evolución natural de los tumores estromales permite resecciones segmentarias más económicas con tasas bajas de recidiva. En los casos de recidiva no subsidiaria de rescate quirúrgico o de enfermedad residual el tratamiento con imantinib mesylate consigue en muchos casos reducciones de la masa tumoral y aumento de la supervivencia.

\section{Bibliografía}

1. Iwashita A. Clinical pathology of gastrointestinal stromal tumor (GIST). Stomach and Intestine 2001; 36: 1113-27.

2. Mochizuki K, Ueda M, Shiozawa S, et al. Imaging of gastrointestinal stromal tumor: relation between $\mathrm{CT}$ findings and grade of malignancy. Nippon Igaku Hoshasen Gakkai Zasshi 2003 May; 63: 210-3.

3. Chang CY, Wang HP, Mao TL, et al. Unusual sonographic appearance of a gastrointestinal stromal tumor presenting as a large multilocular cystic mass. J Clin Ultrasound 2003; 32(4): 200-3.

4. Naitoh I, Okayama Y, Hirai M, et al. Exophytic pedunculated gastrointestinal stromal tumor with remarkable cystic change. J Gastroenterol 2003; 38: 1181-4.
Correspondencia:

Dra. E. Marqués Medina

C/ Dalmacio García Izcara, 8 - $7^{\circ}$ Ctro. E-16004 Cuenca 